\title{
A NECESSÁRIA OBSERVÂNCIA E APLICAÇÃO PRINCIPIOLÓGICA DA MEDIAÇÃO PARA FINS DE TRATAR DE MODO ADEQUADO OS CONFLITOS
}

\author{
SPENGLER, M. F.1; BANDINELLI, T. L.2; MELLO, T³
}

PALAVRAS CHAVE: Autocomposição. Código de Processo Civil. Mediação. Princípios.

\section{RESUMO}

0 acesso à justiça não se encerra na jurisdição estatal. 0 poder judiciário, enquanto meio de acesso à justiça, está exacerbado com o elevado número de demandas que possui. Nesse sentido, a mediação, enquanto método autocompositivo e alternativo de solução de conflitos, possui como objetivo, muito além de gerenciar acordos, pacificar conflitos. 0 foco principal deste instrumento de acesso à justiça é a qualidade e não somente a quantidade. Necessário, contudo, para que ocorra o êxito desse procedimento, o qual tem por característica ser mais célere e humano, a observância de preceitos mínimos que o norteiam. Dessa forma, o presente artigo tem por objetivo analisar, com base na Lei 13.105/2015 (Código de Processo Civil), os princípios que regem o instituto da mediação, com a finalidade de observar de que modo tais preceitos influenciam na atuação coesa do terceiro mediador perante as partes e, se a falta de observância de alguma dessas premissas invalida esse método autocompositivo. Para desenvolver tal estudo, e com vistas a alcançar o objetivo proposto, foi usado como tipo de pesquisa a bibliográfica, a partir da leitura de textos constantes em livros, artigos e diplomas legais. Como método de abordagem utilizou-se o dedutivo, partindo-se da relação entre argumentos gerais, os quais são denominados premissas, para argumentos particulares, até chegar a uma conclusão. 0 resultado baseia-se na ideia de que tais preceitos devem ser analisados e aplicados na sua integralidade, uma vez que são essenciais para o bom andamento e sucesso da mediação como um todo.

\section{THE NECESSARY OBSERVANCE AND PRINCIPIOLOGICAL APPLICATION OF MEDIATION FOR THE PURPOSE OF PROCESSING CONFLICTS PROPERLY}

KEYWORDS: Self-composition. Code of Civil Procedure. Mediation. Principles.

\begin{abstract}
Access to justice does not end with state jurisdiction. The judiciary, as a means of accessing justice, is exacerbated by the high number of demands it has. In this sense, mediation, as a self-composing and alternative method of conflict resolution, has the objective, far beyond managing agreements, pacifying conflicts. The main focus of this instrument of access to justice is quality, not just quantity. However, it is necessary for the success of this procedure to occur, which is characterized by being faster and more humane, observing the minimum precepts that guide it. Thus, this article aims to analyze, based on Law 13.105 / 2015 (Code of Civil Procedure), the principles that govern the mediation institute, in order to observe how these precepts influence the cohesive
\end{abstract}

\footnotetext{
1 Pós-Doutora em Direito, Professora da graduação e da pós graduação da UNISC, Líder do grupo de pesquisa Políticas Públicas no Tratamento dos conflitos, Bolsista de Produtividade em Pesquisa do CNPq. E-mail: fabiana@unisc.br

1 Graduada em direito pela Universidade de Santa Cruz do Sul - UNISC. E-mail: lauratbandinelli@gmail.com.

${ }^{1}$ Acadêmica do curso de Direito na Universidade de Santa Cruz do Sul - UNISC. E-mail: thaismello aula@hotmail.com
} 
performance of the third party mediator before the parties and, if the lack of observance of any of these premises invalidates this self-composing method. To develop such a study, and in order to achieve the proposed objective, the bibliographic type of research was used, based on the reading of texts contained in books, articles and legal diplomas. As a method, the hermeneutic was used, since there was an interpretation of the readings performed. The result is based on the idea that such precepts must be analyzed and applied in their entirety, since they are essential for the smooth progress and success of mediation.

\section{INTRODUÇÃO}

O conflito é inerente ao ser humano. Por tal motivo, inclusive, que a jurisdição estatal, como um todo, está esgotada com o elevado número de processos existentes. Nesse ponto, importante ter-se em mente que o direito de acesso à justiça, além da vertente formal perante os órgãos judiciários, implica, acima de tudo, ao acesso à ordem jurídica justa, para além da jurisdição estatal.

Necessário, então, estabelecer políticas públicas de tratamento adequados dos problemas jurídicos ou não e dos conflitos de interesses existentes, como forma de organizar, não somente os serviços prestados nos processos judiciais, mas também os que possam sê-lo mediante outros mecanismos de solução de conflitos, sobremaneira, os consensuais.

O Código de Processo Civil de 2015 (Lei 13.105/2015) trouxe como uma de suas funções a de incentivar os métodos alternativos para a resolução dos conflitos, especificadamente, pela realização de conciliações e mediações. Busca-se analisar no presente texto a mediação, como método autocompositivo de solução de conflitos, estritamente, no que concerne aos seus princípios, previstos no artigo 166 do Código de Processo Civil.

Primeiramente, se analisará, de maneira sucinta, a mediação como forma de acesso à justiça. Posteriormente o papel do mediador estará em foco e, por fim, todos os princípios expressos no artigo 166 do Código de Processo Civil serão descritos e esclarecidos.

0 objetivo do presente artigo é o de responder: de que modo os princípios dispostos no artigo 166 do Código de Processo Civil (independência, da imparcialidade, da autonomia da vontade, da confidencialidade, da oralidade, da informalidade e da decisão informada) influenciam sobre a conduta do mediador para com as partes e do resultado da mediação como um todo. Aliás, será analisado se a falta de observância desses preceitos invalida esse método autocompositivo de solução dos conflitos.

Todos os princípios dispostos na lei processual civil vigente, no que concerne a mediação, demonstram importância e um valor efetivo. A forma como o mediador age é elemento determinante do desfecho do litígio. Tais preceitos, por sua vez, formam a base da mediação, a visão sistêmica dos princípios permite compreender o que é essa forma autocompositiva de conflitos em sua profundidade.

Com o objetivo de desenvolver este fim, a metodologia empregada contou com o método de abordagem dedutivo, partindo-se da relação entre argumentos gerais, os quais são denominados premissas, para argumentos particulares, até chegar a uma conclusão. Como método de procedimento foi utilizado o método monográfico, a partir da leitura e fichamentos de fontes bibliográficas ligadas ao tema da pesquisa. 


\section{MEDIAÇÃO: MEIO DE ACESSO À JUSTIÇA}

Para fins de discutir o acesso à justiça como um direito humano fundamental é importante antes definir tal expressão. Assim, parafraseando Mauro Cappelletti e Bryant Garth (1988), pode-se dizer, com simplicidade, que este tema está amplamente ligado ao binômio possibilidade-viabilidade de acessar o sistema jurídico em igualdade de condições. Esta prerrogativa foi democraticamente conquistada pelos cidadãos, sob a forma de "o mais básico dos Direitos Humanos". Liga-se, também, à busca de tutela específica para o direito e/ou interesse ameaçado e, por óbvio, com a produção de resultados justos e efetivos.

Esta preocupação evidencia a permanente procura pela efetividade do direito e da justiça no caso concreto. Nasce desvinculada de seu gene quando da dedução em juízo, ou melhor, no processo, procura-se apenas a obtenção de sua conclusão formal, pois o resultado final almejado em qualquer querela deve ser, na sua essência, pacificador do conflito. É só assim que se estará efetivando a chamada Justiça Social, expressão da tentativa de adicionar ao Estado de Direito uma dimensão social (BOLZAN DE MORAIS; SPENGLER, 2019).

0 direito ao acesso à justiça está consubstanciado como fundamental nas constituições político-jurídicas dos Estados Democráticos de Direito, sendo um dos direitos mais básicos dos seres humanos (VASCONSCELOS, 2008). Nesse interim, é de ser em mente que o acesso à justiça não se acaba no Poder Judiciário, sendo este uma das formas daquele. Isso quer dizer que o Poder Judiciário, enquanto jurisdição, é uma das formas de se acessar a justiça, mas não a única.

Todavia, é de notório saber que a jurisdição estatal está exacerbada com o elevado número de demandas que possui, isso provavelmente pela noção geral de que somente por meio do Poder Judiciário é que os conflitos serão resolvidos.

Nesse sentido, a adoção de métodos alternativos de resolução de conflitos é uma tendência que vem sendo estimulada não somente em decorrência dos problemas da jurisdição estatal como um todo, mas também pela existência de cada vez mais conflitos entre os seres humanos. Assim, tornou-se necessária a evolução da sociedade rumo a uma cultura participativa. Tal cultura busca a solução dos conflitos por meio do diálogo e do consenso.

Não se pretende a substituição da jurisdição estatal pelos mecanismos alternativos de solução de conflitos, o que se pretende é a coexistência de todos os métodos alternativos acessiveis para que se configure um sistema adequado para composição efetiva das controvérsias verificadas (TARTUCE, 2008). Nesse sentido, tem-se o entendimento de Spengler (2017, p. 69):

\footnotetext{
... a mediação e a conciliação enquanto políticas públicas são alternativas que pretendem mais do que simplesmente desafogar o Judiciário, diminuindo o número de demandas que a ele são direcionadas. 0 que se espera delas é uma forma de tratamento dos conflitos mais adequada, em termos qualitativos.
}

Para se concretizar um dos objetivos do presente artigo, importante torna-se a descrição da mediação, enquanto método autocompositivo de solução dos conflitos. Esta não tem só por objetivo gerenciar acordos, mas sim pacificar os conflitos, sejam eles simples ou complexos. Tal procedimento visa muito mais a qualidade do que a quantidade. Assim, a mediação, enquanto meio não adversarial, desenvolve um processo com a expectativa de que todos os envolvidos cooperem, para se chegar a um resultado positivo (CAHALI, 2012). 
Tal método consiste na atividade de facilitar a comunicação entre os envolvidos para propiciar que estes mesmos possam, visualizando melhor os meandros do conflito, protagonizar uma solução consensual (TARTUCE, 2008). Nesse sentido, Fernanda Tartuce (2008, p. 208) explica que "a proposta da técnica é proporcionar um outro ângulo de análise aos envolvidos: em vez de continuarem as partes enfocando suas posições, a mediação propicia que elas voltem sua atenção para os verdadeiros interesse envolvidos."

Dessa forma, a vantagem da mediação sobre os demais métodos é que ela permite a continuidade da relação entre os envolvidos em uma perspectiva de futuro (TARTUCE, 2008). De acordo com o Código de Processo Civil, a atuação da mediação será preferencialmente nos casos em que houver vínculo anterior entre as partes, auxiliando, dessa maneira, os interessados na compreensão das questões e dos interesses em conflito. Os envolvidos, por si só, mediante o restabelecimento da comunicação, irão identificar soluções consensuais que gerem benefícios mútuos.

\section{O PAPEL DO MEDIADOR}

0 terceiro, denominado mediador, possui uma função indeclinável nas relações continuadas. Como se depreende, o seu papel não está ligado ao poder de decisão, visto que não se trata de jurisdição e sim sobre a condução e auxílio para a resolução de um litígio.

O mediador não decide, apenas fomenta o diálogo, por isso não se pode perder de vista a importância do papel desempenhado em prol uma sociedade cada vez mais complexa, plural e multifacetada, produtora de demandas, que, a cada dia, superam-se qualitativa e quantitativamente (SPENGLER, 2019).

Em vez de se posicionar de forma superior às partes, o mediador se encontra no meio delas, partilhando de um espaço comum e participativo, voltado para a construção do consenso. 0 mediador deve oferecer às pessoas liberdade para tratar o conflito. Com o auxílio de um mediador, os conflitantes aparam as arestas e as divergências, compreendem as emoções reprimidas e buscam o consenso, objetivando atender aos interesses dos envolvidos, com vistas à pacificação social (SPENGLER, 2019).

0 mediador, guiado por sua base principiológica, deverá ser imparcial e um real facilitador no que diz respeito a comunicação, visto que propicia aos mediandos a examinarem suas divergências e expressarem suas metas e interesses buscando um caminho em comum.

Dessa forma, segundo o entendimento de Tartuce (2016, p. 275) "o mediador precisa ser apto a trabalhar com resistências pessoais e obstáculos decorrentes do antagonismo de posição para restabelecer a comunicação entre os participantes". No mesmo liame, o mediador, por meio do incentivo ao diálogo amigável, estimula as partes para a realização de um acordo satisfatório para ambas, auxiliando na criação de uma nova realidade (SALES; VASCONCELOS, 2006, p. 72).

0 mediador, enquanto terceiro facilitador do instrumento autocompositivo, tem papel fundamental para que isso se realize e concretize com êxito. Aliás, o mediador atua de forma essencial para que a construção do consenso e da harmonia, em um pertencer comum, ocorra em uma mesma relação de hierarquia para com/entre as partes. Para tanto, deverá compreender o conflito, as desavenças, as angústias, para que somente assim consiga, conduzir os mediandos a facilitação de um diálogo. 
À guisa de exemplo, acerca da função do mediador nos litígios podemos citar Sales (2006, p. 81):

\begin{abstract}
O mediador deve aprofundar seus conhecimentos na resolução de conflitos e perceber que os problemas reais, muitas vezes, encontram-se implícitos nas questões aparentes. Ao bom mediador não cabe determinar quem está certo ou errado, pois o que é aparente muitas vezes não condiz com a realidade. 0 que parece simples pode ser complexo. 0 mediador não pode esquecer de que está lidando com pessoas, não com cálculos precisos para os quais existe uma resposta certa. A atuação do mediador é contínua e dialética. 0 mediador deve adotar um diálogo transformador, ou seja, um diálogo construtor que venha a transformar a relação entre as partes. Através do diálogo, o mediador deve transformar a realidades dos conflitos, frisando que não há apenas uma saída ou somente uma lógica universal de ganhar e de perder.
\end{abstract}

Cumpre obtemperar, todavia que ao mediador não incumbe o poder de decisão e sim a condução e o auxílio para comunicação. Dessa forma, é importante que o mesmo possibilite e viabilize a livre iniciativa das partes a fim de que haja o reconhecimento dos interesses comuns e suas possíveis direções para uma solução satisfatória.

É de ser relevado que o terceiro mediador, geralmente, não possui um papel central nas relações continuadas, visto que possui papel secundário não podendo unilateralmente obrigar as pessoas a resolverem a contenda ou impor decisão (SPENGLER, 2018, p. 106). Consoante noção, o mediador deverá ser imparcial, propiciando aos mediandos um ambiente contributivo e participativo com o intuito precípuo da promoção da comunicação.

Convém ponderar que o terceiro mediador "se posiciona em meio as partes partilhando de um espaço comum e participativo, voltado para a construção do consenso em um pertencer comum" (SPENGLER, 2018, p. 105).

Não há falar-se em mediação sem que haja o mediador como figura facilitadora dos conflitos e os mediandos como protagonistas de sua solução. Nesse liame, cada figura presente no procedimento mediativo, dentro de suas limitações, se tornam imprescindíveis para que haja êxito nessas relações.

Embora não possua poder de decisão, ele instrui o andamento de forma adequada a solução dos conflitos, o qual determina o sucesso ou não do desfecho de cada caso concreto. Por conseguinte, é evidente que o terceiro, denominado mediador, por estar no centro do conflito, possua importante atribuição no tocante a relação com/entre as partes.

Merece destaque acerca do papel do mediador, tendo em vista que este se posiciona em meio aos mediandos, partilhando de um espaço comum e participativo, voltado para a construção do consenso em um pertencer comum (SPENGLER, 2017, p. 30).

\title{
4 PRINCÍPIOS DA MEDIAÇÃO - ARTIGO 166, CÓDIGO DE PROCESSO CIVIL
}

Necessário ter-se em mente que, além dos princípios que serão tratados, os quais estão dispostos no artigo 166 do Código de Processo Civil, há também mais duas normas que trazem tais preceitos, quais sejam: a Lei 
Brasileira de Mediação (Lei 13.140/2015), em seu art. $2^{\circ}$, o Código de Ética dos Mediadores na Resolução $125 / 2010$ do CNJ, anexo III, em seu art. $1^{\circ}$

Nesse ponto, há de se ressaltar que os princípios que se repetem em ambas são: imparcialidade do mediador, confidencialidade, e autonomia da vontade das partes. Os princípios que se repetem somente na Lei de Mediação e no Código de Processo Civil são os princípios da oralidade e informalidade, enquanto que no Código de Ética dos Mediadores e no Código de Processo Civil, repetem-se os princípios da decisão informada e da independência.

Ainda, em se tratando individualmente de tais normais legais, a Lei de Mediação trata do princípio da isonomia das partes, da busca do consenso e da boa-fé, enquanto o Código de Ética dos Mediadores, restritamente, trata do princípio da competência, do respeito à ordem pública e às leis vigentes, do empoderamento e da validação.

Nas palavras de Fernanda Tartuce (2016, p. 33): “dentre as previsões, destacam-se como princípios repetidamente mencionados em diferentes normas a imparcialidade, a oralidade, a autonomia da vontade, a informalidade e a confidencialidade". Estes princípios são deveres dos mediadores (por exemplo, atuar com imparcialidade), bem como garantias (independência).

Para o bom andamento da mediação, é de suma importância que o terceiro, titulado mediador, atue conforme tais princípios, uma vez que seu modo de agir é um elemento que determina o sucesso ou não do procedimento.

A palavra princípio dá a ideia de ponto de partida, assim como de norte para orientar a aplicação da norma, de modo que tais preceitos ajudam a entender o espírito da lei, a sua aplicação, a integração com outras normas, bem como norteiam as condutas do mediador (NUNES, 2016).

A partir de agora será analisado, de forma detalhada, cada um dos princípios dispostos no artigo 166 do Código de Processo Civil, quais sejam: princípios da independência, da imparcialidade, da autonomia da vontade, da confidencialidade, da oralidade, da informalidade e da decisão informada, a fim de que se possa ter entendimento acerca destes, bem como para que se possa analisar de que maneira tais preceitos influenciam sobre o andamento da mediação e da conduta do mediador e se a falta de observância de um deles invalida este método autocompositivo.

Nas palavras de Bacellar e Marques (2016, p. 30) "a conciliação e a mediação passam a ser, elas próprias, verdadeiros processos com seus princípios, critérios, formas que determinam uma sequência lógica e adequada de procedimentos com começo, meio e fim."

O princípio da independência é uma verdadeira garantia do mediador, o qual deverá ter autonomia e liberdade para atuar. Nesse sentido, do início ao final do procedimento deverá agir livre de pressões, conforme a ética, a legalidade e o direito (NUNES,2016).

Nesse prisma, tal princípio pressupõe ao mediador a ausência de pressão, sejam elas internas ou externas ou, quanto aos resultados e condições do procedimento (SPENGLER, 2017). Ademais, para Spengler (2017), tal princípio estabelece que o mediador não pode possuir relações estreitas com os mediandos, dado que neste caso a tendência é de agir de forma parcial.

0 princípio da imparcialidade, por sua vez, diz respeito à impossibilidade de o mediador privilegiar um dos litigantes sobre os demais, é por ser imparcial que não deve se posicionar a favor de nenhum dos lados, 
privilegiando as escolhas pessoais de cada um e o diálogo (SPENGLER, 2017). Na medida em que o mediador auxilia na construção do diálogo e na clarificação dos problemas, auxiliando os mediandos a criar opções na busca pelo consenso, ele precisa ser equidistante em relação as partes, não podendo apresentar ideias (NUNES, 2016), não pode sugerir soluções, somente pode ampliar a discussão, sendo a sua postura mais passiva em relação ao mérito (BACELLAR; MARQUES, 2016).

Este princípio representa a garantia de um proceder ético, o processo de mediação, somente sob sua base pode ser utilizado na condução das partes a um acordo (MENDONÇA, 2014). Partindo da ideia de que a imparcialidade é a conduta do mediador de não favorecer nenhum dos mediandos, é elemento intrínseco à conduta do mediador e que não pode se afastar dele, sob pena de colocar em risco todo o procedimento da mediação.

Portanto, é nesse sentido que se dá o princípio da imparcialidade, já que o mediador, atua como um facilitador, não pode implicar sugerir, nem influenciar, sobre os mediandos. Pode ser caracterizado como um interventor com autoridade, mas não deve impor ou estabelecer resultados pelo uso de seu poder e de seu domínio (CALMON, 2008).

Contudo, em tal ponto, faz-se necessário diferenciar imparcialidade de neutralidade, já que por muitas vezes ambas são usadas como sinônimos na linguagem comum. Para Mendonça (2014, p. 28):

Todo mediador pode se manter imparcial, mas nenhum mediador pode ser neutro, já que a
emoção é da natureza do homem, e todo ser humano pauta sua conduta em crenças e
convicções íntimas, que se materializam em uma ação impulsionada pela emoção, a partir
de seu conteúdo cognitivo, desiderativo e valorativo.

Nesse contexto, de fato, é do terceiro, a responsabilidade pelo andamento das atividades, sendo que para as partes, estritamente, cabe à função de preocuparem-se com a matéria em discussão (BOLZAN DE MORAIS; SPENGLER, 2019). A todo momento deve o mediador supervisionar a conduta dos envolvidos, devendo instruí-los para que se portem de forma conveniente perante o procedimento, com a finalidade de obterem a concretização do consenso, isto é, a obtenção de um acordo.

A autonomia da vontade das partes é mais um princípio. Este diz respeito ao poder de decisão dos envolvidos, uma vez que o principal objetivo da mediação é a busca do consenso e isso pressupõe espontaneidade e voluntariedade em todo o processo de diálogo (NUNES, 2016), sendo que os envolvidos devem encontrar a melhor forma do tratamento do conflito.

Outrossim, na medida em que a mediação é fomentada, mas não imposta pela norma legal e pelos operadores, tal preceito tem relação ao interesse e direitos das pessoas para a concordância ou não de querer participar da mediação.

Cabe aos envolvidos, antes, durante e ao final da mediação tomar as decisões, devendo ser respeitados os diferentes pontos de vista e as convicções pessoais. 0 mediador é apenas um indutor de geração de ideias para que os próprios envolvidos descubram os caminhos para boas soluções (NUNES, 2016)

Da mesma forma, pode corresponder às decisões, é opcional aos conflitantes, homologarem ou não o acordo, é de competência deles, optarem pelo melhor para si (SPENGLER, 2017). E, neste sentido: “de fato, o que a mediação propõe é um modelo de justiça que foge da determinação rigorosa das regras jurídicas, abrindo-se à participação e à liberdade de decisão entre as partes”. (BOLZAN DE MORAIS; SPENGLER, 2019, p. 160). 
Pelo princípio da confidencialidade, todas as situações, os fatos e as propostas que foram expostas durante a mediação são sigilosos (FARINELLI; CAMBI, 2014). 0 mediador e os mediandos assumem o compromisso de manter o sigilo do que foi proposto ou discutido durante a sessão, sendo-lhes defeso utilizar as informações ali obtidas para qualquer outro fim (VASCONCELOS 2008).

É de extrema importância, para que as partes se sintam tranquilas no desenvolvimento da mediação, 0 absoluto sigilo do quanto nele se apresenta (CAHALI, 2012). Este é um dos princípios mais importantes da mediação, uma vez que, constitui o maior dever do mediador, o qual nunca poderá revelar o que se passou nas audiências (CALMON, 2008). Contudo, nas palavras de Bacellar e Marques (2016, p.30):

\footnotetext{
Pela confidencialidade, tudo que for conversado durante o processo consensual não será público, permanecerá sigiloso e não poderá servir de prova em eventual processo envolvendo as partes. A confidencialidade estende-se a todas as informações produzidas no curso do procedimento, não podendo ser revelada sequer em processo arbitral ou judicial, salvo se as partes expressamente deliberarem.
}

De tal forma, as discussões feitas pelas partes durante a sessão de mediação deverão remanescer confidenciais. Assim, não se pode divulgar ou utilizar de forma diversa as informações trocadas, dado que permitir o contrário seria autorizar que o acordo fosse entabulado com o propósito de investigar a parte contrária (NERY JUNIOR; ANDRADE NERY, 2018). Este princípio alcança não só o mediador, mas também as partes, seus prepostos e advogados e outras pessoas que tenham participado do procedimento (NERY JUNIOR; ANDRADE NERY, 2018).

Conforme Calmon (2008) é mediante um procedimento voluntário e confidencial, formado em método próprio e informal que se faz a mediação. Atrelado a isso, dá-se o princípio da informalidade. Este implica na "desburocratização na solução de conflitos, uma vez que impera a informalidade nas sessões de mediação ou conciliação." (CUNHA, 2016, p.57).

O princípio da informalidade é atrelado ao da oralidade, sendo que as pessoas têm a oportunidade de debater os seus problemas, com o objetivo de encontrar a solução mais adequada para eles. A postura do mediador contribui para imprimir um caminho mais informal à sessão (SPENGLER, 2017). Por ser um processo informal e flexível, a mediação, além de levar ao mero acordo, pode também solucionar de forma integral o conflito antes existente (NUNES, 2016).

Através de tal princípio é que as pessoas se sentem à vontade para construir as melhores soluções, na medida que informalidade combina espontaneidade, liberdade e criatividade (NUNES, 2016). Além disso, como cita Spengler (2017, p. 149): “o uso de um tom de conversa sem maiores formalidades estimula o diálogo". Em suma, tanto a oralidade, quanto a informalidade são preceitos que tornam este meio autocompositivo (mediação) de tão fácil acesso, tornando desnecessários formalismos e burocracias.

Em regra, não se usa documentos, provas escritas e nem outros recursos não orais, apenas o acordo, ao final da mediação, será escrito. Sendo um complemento da simplicidade, a oralidade é essência do diálogo. 0 consenso é construído com base nas escutas dos envolvidos, na defesa de convicções, e até mesmo de posicionamentos, pela busca da melhor opção (NUNES, 2016). 
A falta de maiores formalidades e a oralidade tornam o procedimento da mediação rápido e eficaz, assumindo, as partes e o mediador, o compromisso de manter o sigilo do que foi proposto e discutido, relacionamse, assim, sem hierarquia (VASCONCELOS, 2008).

O princípio da decisão informada corresponde ao direito que todos os participantes das sessões de mediação possuem de receberem informações, seja de cunho qualitativo, seja quantitativo acerca da composição que estão realizando. 0 objetivo é de que não ocorra uma surpresa por qualquer consequência inesperada da direção ou proposta pela qual resolveram optar (SPENGLER, 2017).

Importa a prerrogativa das partes de se obterem informadas suficientemente da mediação, e de seus direitos, deveres e opções, de modo que a eleição dessa técnica seja a mais consciente possível (MARINONI; ARENHART; MITIDIERO, 2018).

Logo, é encargo do mediador a continuidade do desenvolver processual, "de forma justa e fiel aos princípios que regem seu trabalho e o instituto." (BOLZAN DE MORAIS; SPENGLER, 2019, p. 170). Estes princípios são preceitos mínimos que devem ser seguidos pelo mediador no decorrer da mediação, para que se obtenha o objetivo final concluído.

Por conseguinte, abordar estes princípios é de extrema relevância, visto que este método adequado de solução de conflitos, além de eficaz, é célere. No entanto, essa eficiência e essa celeridade passam por condutas do terceiro facilitador, denominado mediador. E de nada adianta, ser um meio "rápido", se não for proporcionado de maneira satisfatória, com a devida observância dos preceitos legais, denominados princípios.

\section{CONCLUSÃO}

A mediação, enquanto método autocompositivo de resolução de conflitos, está incluída no objetivo maior de garantir acesso à justiça. Tal acesso nunca foi exclusividade do Poder Judiciário, mas sim finalidade do Estado, o qual deve incentivar que os litígios sejam resolvidos no âmbito estatal ou fora dele. Em tal ponto, há de se observar que atuação do mediador, com base nos princípios legais, torna a mediação um meio de acesso à justiça tão eficaz quanto a jurisdição estatal.

O foco da mediação é o conflito e não somente a resolução deste. Busca-se em tal método o restabelecimento de uma convivência com equilíbrio de posições, independentemente de se chegar a uma composição, ainda que esta seja uma consequência. Além disso, um dos principais objetivos da mediação, a qual não serve unicamente como "válvula de escape" do Poder Judiciário, é a inocorrência de novos litígios.

Dessa forma, a partir da análise realizada no presente artigo, averiguou-se que o mediador, enquanto terceiro elemento, encontra-se no centro do conflito. É um terceiro facilitador que, com o uso de suas técnicas adequadas, se dispõe a chegar à obtenção da autocomposição.

Todavia, para que se tenha uma mediação integralmente exitosa, é determinante que o mediador seja responsável, organizado e esteja disposto a auxiliar os envolvidos a buscar uma solução para o litígio em que estiverem envolvidos.

Os princípios da mediação têm como objetivo principal o de preservar a integridade e proteger os envolvidos nela. Em síntese, são preceitos fundamentais para se chegar a um consenso, com base num procedimento baseado de forma coesa com suas regras. 
Nesse sentido, o mediador, além de terceiro facilitador, atua de forma ativa/passiva e, com certeza, sua linha de atuação influenciará, de caso a caso, no deslinde do conflito, apresentando soluções e estimulando os mediandos a uma solução adequada.

De tal maneira, é de suma importância ressaltar-se que todos os princípios dispostos no artigo 166 do Código de Processo Civil sejam aplicados em sua integralidade. Isso porque são indispensáveis tanto para o fundamental papel do mediador, quanto para o sucesso do procedimento em si.

Nesse contexto, com base no objetivo proposto no presente artigo, responde-se que tais princípios influenciam de maneira ativa sobre a conduta do mediador para com as partes e com o resultado da mediação como um todo, na medida em que a maneira como o mediador atua reflete no sucesso ou não do método. Além disso, é de se salientar que a falta de observância de tais princípios pode vir a invalidar este método autocompositivo de resolução de conflitos, simplesmente por descaracterizá-lo ou até mesmo por infringir algum dos pontos principais de tais preceitos.

\section{REFERÊNCIAS}

BACELLAR, R. P; MARQUES, P. Dos auxiliares da justiça. In: CUNHA, J. S. F; CAMBI, E; BOCHENEK, A. C. (Orgs). Código de Processo Civil Comentado. 1. ed. São Paulo: Revista dos Tribunais, 2016. p. 30. E-book: Biblioteca Virtual ProView.

BRASIL. Lei n. 13.104, de 16 de março de 2015. CPC (2015). Código de Processo Civil. Diário Oficial da República Federativa do Brasil, Brasília, DF.

. Lei 13140 de 26 de junho de 2015. Disponível em: < http:// www. planalto.gov.br/ccivil_03/_Ato20152018/2015/Lei/L13140. htm>.Acesso em: 26 jun. 2018.

CAHALI, José Franciso. Curso de arbitragem: mediação, conciliação, resolução CNJ 125/2010. 2. ed. São Paulo: Editora Revista dos Tribunais, 2012.

CALMON, Petrônio. Fundamentos da mediação e da conciliação. Rio de Janeiro: Forense, 2008.

CAPPELLETTI, Mauro. GARTH, Bryant. Acesso à justiça. Porto Alegre: Sérgio Antonio Fabris Editor, 1988, reimpresso em 2002.

CNJ - Conselho Nacional de Justiça. Resolução 125 de 29 de novembro de 2010. Disponível em: <http://www.cnj.jus.br/atos-administrativos/atosda-presidencia/resolucoespresidencia/12243-resolucao-no125-de-29-denovembro-de-2010>. Acesso em: 04 jan. 2020.

CUNHA, J. S. F; CAMBI, E; BOCHENEK, A. C. (coords.). Código de Processo Civil Comentado. 1. ed. São Paulo: Revista dos Tribunais, 2016. E-book: Biblioteca Virtual ProView.

CUNHA, José Sebastião Fagundes. Da audiência de conciliação ou de mediação. In: CUNHA, J. S. F; CAMBI, E; BOCHENEK, A. C. (Orgs). Código de Processo Civil Comentado. 1. ed. São Paulo: Revista dos Tribunais, 2016. p. 57. E-book: Biblioteca Virtual ProView. 
FARINELLI, A; CAMBI, E. Conciliação e Mediação no novo Código de processo civil (PLS 166/2010). In: WALD, Arnoldo (org). Doutrinas Essenciais Arbitragem e Mediação. v.1. São Paulo: Editora Revista dos Tribunais, 2014. p. 25. E-book: Biblioteca Virtual ProView.

MARINONI, L.; ARENHARDT, S.; MITIDIERO, D. Código de processo civil comentado. 4. ed. rev., atual e ampl. São Paulo: Thomson Reuters Brasil, 2018. E-book: Biblioteca Virtual ProView.

MENDONÇA, Angela Hara Buonomo. A reinvenção do uso da mediação. In: WALD, Arnoldo (org). Doutrinas Essenciais Arbitragem e Mediação. v.1. São Paulo: Editora Revista dos Tribunais, 2014. p. 28. E-book: Biblioteca Virtual ProView.

MORAIS, J. L. B. de.; SPENGLER, F. M. Mediação e arbitragem: alternativas à jurisdição! 4. ed. rev. e ampl. Porto Alegre: Livraria do Advogado, 2019.

NERY JUNIOR, N.; ANDRADE NERY, R. Código de Processo Civil comentado. 3. ed. São Paulo: Thomson Reuters Brasil, 2018. Ebook: Biblioteca Virtual Proview.

NUNES, Antonio Carlos Ozório. Manual de Mediação: guia prático da autocomposição. São Paulo: Editora Revista dos Tribunais, 2016. E-book: Biblioteca Virtual ProView.

SALES, Lília Maia de Moraes; VASCONCELOS, Mônica Carvalho (Org.) Mediação familiar: um Estudo HistóricoSocial das Relações de Conflitos nas Família Contemporâneas. Fortaleza: Expressão Gráfica e Editora LTDA, 2006.

SPENGLER, Fabiana Marion. Dicionário de Mediação. Volume II. Santa Cruz do Sul: Essere nel Mondo: 2019 . Mediação de Conflitos: da teoria à prática. 2. ed. Porto Alegre: Livraria do Advogado, 2017. Mediação no direito familista e sucessório. Santa Cruz do Sul: Essere nel Mondo, 2018.

TARTUCE, Fernanda. Mediação nos conflitos civis. 3 ed., rev., atual. e ampl. Rio de Janeiro: Forense. São Paulo: Método, 2016. . Mediação nos Conflitos Civis/Fernanda Tartuce. - Rio de Janeiro: Forense: São Paulo: Método, 2008 VASCONCELOS, Carlos Eduardo de. Mediação de conflitos e práticas restaurativas. São Paulo: Método, 2008. 